\title{
Economic losses due to health hazards caused by haze event in Johor Bahru, Malaysia
}

\author{
Nur H. Hanafi ${ }^{1}$, Mimi H. Hassim ${ }^{1,}$, Zainura Z. Noor ${ }^{1}$, Joon Y. Ten ${ }^{1}$, Nurazimah M. Aris ${ }^{1}$, \\ and A. A. Jalil ${ }^{1}$ \\ ${ }^{1}$ Department of Chemical Engineering/Centre of Hydrogen Energy, School of Chemical and Energy \\ Engineering, Faculty of Engineering, Universiti Teknologi Malaysia, 81310 Johor Bahru, Johor, \\ Malaysia.
}

\begin{abstract}
This study assessed the health risk analysis of haze pollution in Pasir Gudang and Larkin. The relationship between health risk and economic effect due to air pollution exposure in Johor is still poorly understood. Therefore, the objective of this study was to analyse the relationship between air pollution and health. Then, the economic impact due to smoke haze on associated outpatients was calculated. Daily morbidity data from 2014 to 2016 for three haze-related illnesses were collected from two health clinics. Data on air quality were obtained at two Continuous Air Quality Monitoring (CAQM) stations in Johor. Health risks for all age categories in the haze periods were higher than those in non-haze periods. The outpatient morbidity cases in health clinics increased with the rising occurrence of smoke haze in Johor Bahru. The average annual economic losses due to the outpatient health impact of haze were valued at RM83,233 and RM107,486 for Pasir Gudang and Larkin, respectively.
\end{abstract}

\section{Introduction}

The strategic location of Malaysia puts the country in a safe position away from natural disasters such as volcanic eruption and earthquake. Despite the fact that Malaysia does not experience any natural disaster, however, it faces a man-made disaster yearly, which is haze. Haze is a common occurrence in which all Southeast Asian countries experience the event around the second to third quarter of the year. In Indonesia, the technique of slash-andburn for land clearance has been the main cause of haze since 1991 [1]. In 2013, the forest fire in Riau, Indonesia burned more than 3,000 hectares of plantations. In September 1997, in the city of Kuching, East Malaysia, the recorded air pollution index (API) reading was more than 850 , which drew visibility to just less than $10 \mathrm{~m}$. The emission from Indonesian forest fires releases abundant of airborne particles. In the long-range transboundary transport with biomass emissions, haze occurs in Southeast Asia and affects several countries severely, such as Malaysia, Singapore, Thailand, and Indonesia. Haze contains dust and smoke particles, which are made of harmful fine particulate matters. They have been known to cause serious health damage to human if exposed for a long time. Some of the health implications from continuous exposure are irritation in the nose, ear and throat; respiratory system disruption that specifically affects lung; and skin condition such as eczema [1].

In Malaysia, the air quality status is monitored by the Department of Environment (DOE) through a network of 52 automatic stations. Haze is measured in terms of API with a range of values to determine different levels of haze severity. The API ranges are good (0$50)$, moderate (51-100), unhealthy (101-200), very unhealthy (201-300), and hazardous

\footnotetext{
*Corresponding author: mimi@cheme.utm.my
} 
(above 300). The API calculation formula used in Malaysia and other ASEAN countries follow the United States Environmental Protection Agency (US EPA) based on a study on the factors of exposure of pollutants to human health. API is a measurement of the effects of five major air pollutant concentrations (fine particulate matter measuring less than $10 \mu \mathrm{m}$ $\left(\mathrm{PM}_{10}\right)$, carbon monoxide $(\mathrm{CO})$, sulphur dioxide $\left(\mathrm{SO}_{2}\right)$, nitrogen dioxide $\left(\mathrm{NO}_{2}\right)$, and groundlevel ozone $\left(\mathrm{O}_{3}\right)$ ) on a normal human's health over a specific time of exposure. The pollutant with the highest concentration will be automatically selected to calculate the index.

Countries affected by haze would incur productivity losses as a result of haze-related illnesses suffered by the population. Several studies assessing the health-related economic loss caused by haze episodes demonstrated that haze pollution results in adverse effects on public health. Productivity losses occurred in terms of foregone production opportunities during the idled workdays of hospital admission and sick leaves obtained by a fraction of the population at risk, as well as reduced activity days. Valuing the damage caused by haze will help policymakers appreciate the scale of the problem as the values can be readily compared with other losses. The assessment of impact facilitates the establishment of a common crosscountry environmental policy framework, which will benefit the affected region as a whole. An investigation on the economic value of June 2013 Haze Impacts on Peninsular Malaysia was reported by Mohd Shahwahid [2], which applied questionnaires and interviewed respondents about haze impacts on health, lifestyle, travel, and occupational-related issues. The finding showed the total economic loss of RM1.5 billion $(0.48 \%$ of 2013 gross domestic product (GDP)). Jamal et al. [3] conducted a study about the economic effect from the impact of haze on associated inpatient cases in Kuala Lumpur and Selangor from 2005 to 2009. This study used dose-response function (DRF) to estimate the number of incremental health cases to show the relationship between PM $10 / \mathrm{API}$ and haze-related illnesses. The authors estimated the cost of illness (COI) based on the incremental cost of treatment and loss of productivity due to illnesses attributed to haze (for four years). The result found an average of 19 hazy days/year with $31 \%$ total increase of the inpatient rate during the haze event. Then, the average annual cost of inpatients due to haze was valued at RM273,000 (USD91,000) and the resulting estimated economic loss in Kuala Lumpur and Selangor from 2005 to 2009 was RM14,368 per hazy day.

A study in Shanghai reported by Yin et al. revealed that health costs due to haze pollution in 2009 were 2.46 billion Chinese Yuan, accounting for approximately $0.17 \%$ in the GDP of the city [4]. In Beijing, a study concluded that the adverse health effects of highlevel $\mathrm{PM}_{2.5}$ exposure during the haze that occurred on January $10^{\text {th }}$ to $15^{\text {th }}, 2013$ led to about 489 million Chinese Yuan of health-related economic loss, and more than $90 \%$ was attributable to premature deaths, acute bronchitis, and asthma [5]. Another study from Beijing suggested that the haze events in January 2013 might lead to 253.8 million dollars of healthrelated economic losses, accounting for $0.08 \%$ of the total 2013 annual GDP of Beijing [6]. This study used simulated $\mathrm{PM}_{2.5}$ concentration, which was verified with meteorology and air quality measurements, and DRF from epidemiology study and gridded population data to determine the health impact of haze. A study conducted by $\mathrm{Mu}$ and Zhang evaluated the direct economic loss of the haze event in January 2013 in China based on the available data from 20 provinces (cities). The authors estimated that the cost due to increased demand for outpatient and emergency services caused by haze pollution was nearly twice that during non-haze periods in China, which accounted for $98 \%$ of the total haze-related economic losses (23 billion Chinese Yuan) [7].

Although fewer studies have assessed the economic effect of the health impact due to haze, but there is still poor understanding of the relationship between health risk and economic effect due to air pollution exposure in Johor, which is located in the southernmost part of Peninsular Malaysia. In this research, the levels and health risk of $\mathrm{PM}_{10}$ in haze and non-haze periods in Pasir Gudang and Larkin were investigated through a risk-based 
approach. Then, the relationship between air pollution and health risk in these two locations was analysed. Lastly, the economic impact due to the smoke haze on associated outpatient cases at selected health clinics in Johor Bahru on morbidity for three selected years (2014, 2015, and 2016) was examined. Health-related economic losses were also calculated and the findings of this study are important to provide scientific basis of the transboundary haze hazard for the implementation of air pollution control strategies.

\section{Methodology}

\subsection{Selection of the study area}

With prevailing winds blowing north-eastward during the haze period, prolonged and large-scale forest fires in Sumatra and Kalimantan are almost certain to bring plumes from fires in Borneo to the southern part of Malaysia, especially Johor. Therefore, this study was conducted in Larkin and Pasir Gudang, Johor. Figure 1 shows two of the Continuous Air Quality Monitoring (CAQM) and nearby health clinics located at the urban areas of Johor.

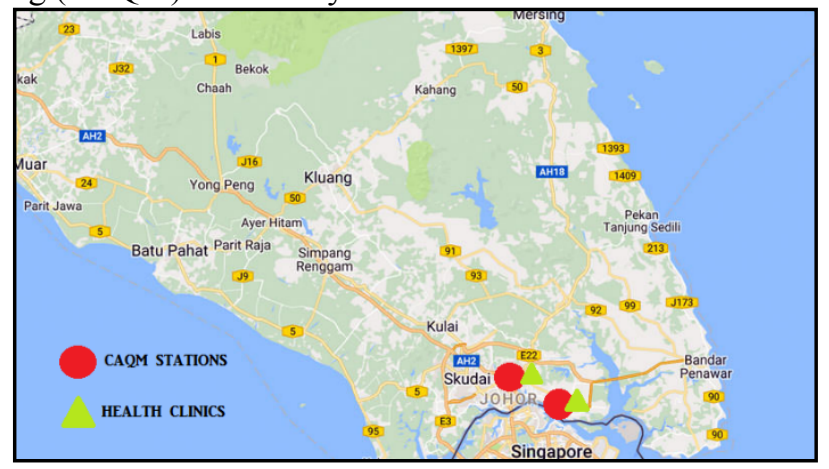

Fig. 1. Spatial distribution of Continuous Air Quality Monitoring stations and studied health clinics in Johor.

\subsection{Data needs and sources}

After the areas (locations) of the study had been decided, data were collected to acquire relevant data for the study, including the air quality data from the Ministry of Natural Resources and Environment, database on visitation rates, health treatment (outpatients), and illness types that could be obtained from the selected public hospitals and clinics.

\subsubsection{Air quality data}

Data on air quality in two CAQM stations in Johor were obtained from the Department of Environment (DOE), which is operated by Alam Sekitar Malaysia Sdn. Bhd. (ASMA). The data composed of mean daily ambient concentrations of particulate matter less than 10 $\mathrm{mm}\left(\mathrm{PM}_{10}\right)$ in $\mathrm{mg} \mathrm{m}^{-3}$. The data are reliable and fit for the purpose of research work since the monitoring instruments and operation protocols for the CAQM stations in Malaysia are approved by the US EPA. Quality control protocols governing fieldwork, analysis and data handling, analysis, and interpretation are implemented by ASMA on a regular basis.

\subsubsection{Health clinics outpatient data}

Monthly and annual data of morbidity for outpatients during the haze and non-haze periods were obtained from health clinics of the Ministry of Health (MOH) Malaysia via the 
Health Informatics Centre (HIC). The two health clinics in both rural and urban areas adjacent to CAQM stations were chosen. Data including gender, age group, and type of disease diagnosis adhered to the World Health Organization's International Classification of Disease (ICD 10) for haze-related illnesses were obtained from January 2014 until December 2016.

\subsection{Dose-response assessment}

Based on the work done by Zhao et al. [8], the health risk assessment due to inhalation mode of exposure to haze pollution was done based on the estimated dose rate of each pollutant and the lowest observed adverse effect levels (LOAELs). The population is divided into two age-specific categories, namely children $(<12$ years old) and adults $(>13$ years old). The dose rate for pollutant was estimated through the following expression $[9,10]$ :

$$
\text { Dose Rate }(D)=(B R / B W) \int_{0}^{24} C(t) O F(t) d t
$$

Where $D$ is the age-specific dose rate $\left(\mathrm{g} \mathrm{kg}^{-1}\right), B R$ is the age-specific breathing rate ( $\mathrm{L} \mathrm{min}^{-}$ $\left.{ }^{1}\right), B W$ is the age-specific body weight $(\mathrm{kg}), C(t)$ is the concentration of each pollutant $\left(\mathrm{g} \mathrm{m}^{-}\right.$ ${ }^{3}$ ), and $O F(t)$ is the occupancy factor (percentage of population likely to be in the building at a given interval of time). LOAELs are defined as the lowest tested doses of pollutants that have been reported to cause harmful (adverse) health effects on people or animals.

Table 1. Breathing rate, body weight, and LOAEL values for morbidity.

\subsection{Risk}

\begin{tabular}{|c|c|c|c|}
\hline $\begin{array}{c}\text { Age-Specific } \\
\text { Category }\end{array}$ & $\begin{array}{c}\text { Breathing } \\
{\text { Rate }\left(\mathbf{m}^{3}\right.}^{\mathbf{3}} \\
\left.\text { day }^{-1}\right)\end{array}$ & $\begin{array}{c}\text { Body } \\
\text { Weight } \\
(\mathbf{k g})\end{array}$ & LOAEL \\
\hline $\begin{array}{c}\text { Children (< 12 } \\
\text { years old) }\end{array}$ & 10.0 & 30.0 & 20.9 \\
\hline $\begin{array}{c}\text { Adults (> 13 years } \\
\text { old) }\end{array}$ & 20.0 & 70.0 & 14.7 \\
\hline
\end{tabular}

\section{characterisation or estimation of health risk}

Health risk characterisation or estimation of health risk was calculated based on the exposure and dose-response assessments. Heath risk is normally characterised separately for non-carcinogenic and carcinogenic effects. The health risks can be calculated with the following equation $[9,10,11,12]$ :

Health Risk $(H R)=[($ Dose rate $) /($ Pollutant - Specific LOAEL $)]$

$\mathrm{HR}$ is dimensionless and useful for making relative comparisons. The results were validated based on the historical data on air quality and health data. Those age categories that have higher health risk values will be classified as a 'sensitive' group.

\subsection{Economic value in Johor}

In this research, the economic effect of the impact of haze pollution on the associated outpatient cases at the selected health clinics in Johor from 2014, 2015, and 2016 was estimated. The relationship between haze pollutant concentrations, i.e., $\mathrm{PM}_{10}$ or API value, and haze-related illness was estimated via DRF. The economic value for the health impact was estimated by multiplying the dose-response or risk coefficient, as well as the population at risk and the unit economic value with the change in ambient concentration. The economic values $(\mathrm{EV})$ of outpatient health costs due to the haze in Johor can be calculated by using the following formula [14]: 
Where

$$
E V=\beta^{*}(1+F)^{*} H^{*} H D^{*} P O P N^{*} U E V
$$

$\mathrm{EV}=$ Economic values of outpatient health costs of healthcare facilities in the study area, $\beta=$ Risk estimate or dose-response coefficient for all haze-related illnesses,

$\mathrm{F}=$ Adjustment factor to include outpatients in private hospitals and self-treated patients, $\mathrm{DH}=$ Average incremental change in the air pollutant level (relative to normal level), e.g., $\mathrm{PM}_{10}$ concentration,

$\mathrm{HD}=$ Number of hazy days,

POPN $=$ Population size in the study area (population at risk), and

$\mathrm{UEV}=$ Average unit EV for health clinics outpatients.

\section{Results and discussion}

\subsection{Health risk assessment}

Table 2 provides the average API values and the average daily morbidity cases of hazerelated illness for Pasir Gudang and Larkin in 2014, 2015, and 2016. The table shows that the highest average API value was $66.2 \pm 104.9$ in 2015 recorded in Pasir Gudang. This is the worst reading of haze pollution concentration where the status of the average API reading exceeded the 'good condition' level in September 2015. Unfortunately, this caused higher number of morbidity cases $(13,245.3 \pm 1,419.9)$ due to haze-related illnesses. i.e., conjunctivitis, upper respiratory tract infections (URTI), and asthma. This reading is worsened as there are many other confounding factors such as cigarette smoke, indoor pollutants, open burning, motor vehicle combustion, and industrial emissions in Pasir Gudang, which is also the densest industrial city in Johor. Daily morbidity cases of outpatients for Pasir Gudang and Larkin were plotted along with PM $_{10}$ concentration and average API levels in Figure 2 to provide more insights on the difference in outpatient morbidity cases between normal and hazy years. The plot of outpatient cases shows a clear incremental change during the haze event (in 2015) relative to non-haze events. The figure also indicates that $\mathrm{PM}_{10}$ increased faster relative to API values as the transboundary smoke haze loomed and subsequently increased the number of morbidity cases of haze-related illness.

Table 2. Average air pollution index values and average daily morbidity cases of haze-related illness.

\begin{tabular}{|c|c|c|c|c|c|c|c|}
\hline & \multicolumn{3}{|c|}{ Pasir Gudang } & \multicolumn{3}{|c|}{ Larkin } \\
\hline & & 2014 & 2015 & 2016 & 2014 & 2015 & 2016 \\
\hline \multicolumn{2}{|c|}{ Average API } & $58.7 \pm 103.3$ & $66.2 \pm 104.9$ & $55.0 \pm 103.3$ & $49.6 \pm 103.8$ & $55.76 \pm 103.2$ & $49.36 \pm 104.7$ \\
\hline \multirow{3}{*}{$\begin{array}{c}\text { Average } \\
\text { Morbidity } \\
\text { Cases }\end{array}$} & $\begin{array}{c}\text { Children } \\
(<12 \text { years } \\
\text { old })\end{array}$ & $1131.1 \pm 59.1$ & $3190.6 \pm 452.0$ & $1077.5 \pm 85.8$ & $370.5 \pm 82.4$ & $393.3 \pm 34.2$ & $321.3 \pm 71.7$ \\
\hline & $\begin{array}{l}\text { Adults (> } \\
13 \text { years } \\
\text { old) }\end{array}$ & $6902.7 \pm 647.6$ & $10054.7 \pm 1040.6$ & $6536.0 \pm 565.0$ & $2972.3 \pm 481.3$ & $3509.6 \pm 645.5$ & $2945.8 \pm 266.9$ \\
\hline & Total & $8033.8 \pm 642.7$ & $13245.3 \pm 1419.9$ & $7608.0 \pm 644.6$ & $3340.6 \pm 474.5$ & $3831.3 \pm 636.2$ & $3339.0 \pm 280.8$ \\
\hline
\end{tabular}


Avg. Morbidity Cases

Avg. API/ PM10 Conc.

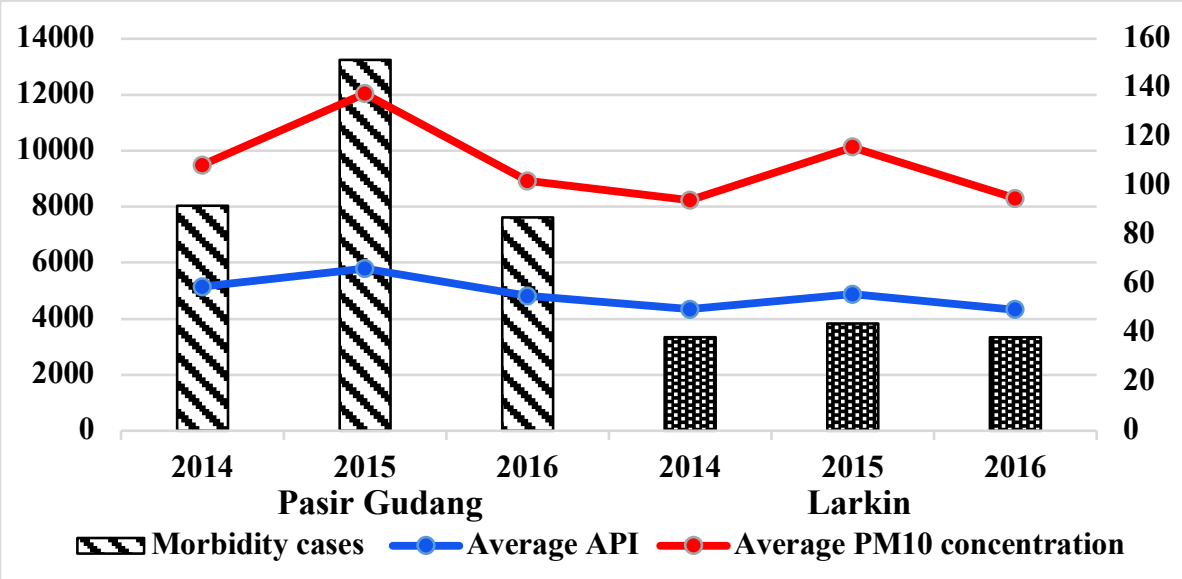

Fig. 2. Trend of morbidity cases of outpatient cases with average API values and $\mathrm{PM}_{10}$ concentration

Dose rates were obtained for two age categories of children and adults in Pasir Gudang and Larkin in 2014, 2015, and 2016. The dose rates and health risk values for these cities in terms of average $\mathrm{PM}_{10}$ concentration are shown in Table 3. It is observed that the dose rates for all groups in the haze period, which is in 2015, are higher than those in non-haze periods. This also indicates that the health risks for all age categories are also higher during haze periods. In comparison, the dose rates for children are always higher than adults, which indicates that young children are more prone to health risks. As young children are still undergoing development in central nervous, reproductive, immune, and digestive systems [15], the exposure to environmental toxicants can lead to irreversible damage. The World Health Organization (WHO) [15] also claimed that air pollution brings a major environmentrelated health threat to children and a risk factor for acute and chronic respiratory diseases.

Table 3. Dose rates and health risk values for different age categories due to $\mathrm{PM}_{10}$ in haze and non-

\begin{tabular}{|c|c|c|c|c|c|c|c|}
\hline & \multirow{2}{*}{$\begin{array}{c}\text { Age } \\
\text { Categories }\end{array}$} & \multicolumn{3}{|c|}{ Pasir Gudang } & \multicolumn{3}{|c|}{ Larkin } \\
\hline & & 2014 & 2015 & 2016 & 2014 & 2015 & 2016 \\
\hline \multirow[t]{2}{*}{$\begin{array}{c}\text { Dose Rate ( } \mu \mathrm{g} \\
\left.\mathrm{kg}^{-1}\right)\end{array}$} & $\begin{array}{c}\text { Children } \\
\text { (<12 years } \\
\text { old })\end{array}$ & $3314.3 \pm 645.6$ & $4759.7 \pm 2404.7$ & $3136.7 \pm 585.7$ & $2966.9 \pm 676.1$ & $3998.7 \pm 1756.9$ & $3035.6 \pm 501.9$ \\
\hline & Adults & $2840.8 \pm 553.4$ & $4079.8 \pm 2061.2$ & $2688.6 \pm 502.1$ & $2543.1 \pm 579.5$ & $3427.5 \pm 1505.9$ & $2601.9 \pm 430.3$ \\
\hline \multirow[t]{2}{*}{ HR } & $\begin{array}{c}\text { Children } \\
\text { (<12 years } \\
\text { old })\end{array}$ & $120.5 \pm 19.1$ & $126.9 \pm 23.5$ & $103.3 \pm 15.1$ & $113.1 \pm 19.8$ & $132.92 \pm 19.1$ & $128.6 \pm 19.9$ \\
\hline & Adults & $82.9 \pm 7.2$ & $85.2 \pm 8.4$ & $77.6 \pm 11.2$ & $79.8 \pm 8.48$ & $87.55 \pm 7.3$ & $85.9 \pm 7.2$ \\
\hline
\end{tabular}

haze periods.

\subsection{Economic value of haze events}

This study focuses on estimating the haze impact for three years based on the total population of Pasir Gudang and Larkin. Based on the results from the unit economic value of RM1 for health clinics, the economic loss due to outpatient health impact of haze for Pasir Gudang and Larkin are valued at RM83,233 and RM107,486, respectively. The economic 
valuation of health impact is important to better appreciate the scale of the haze hazard in relation to other health, social, or environment problems.

Table 4. Cost of illness from haze event in Johor population.

\begin{tabular}{|l|c|c|l|}
\hline \multirow{2}{*}{ Item } & \multicolumn{2}{|c|}{ Parameter } & \multirow{2}{*}{ Data Source } \\
\cline { 2 - 3 } & $\begin{array}{c}\text { Pasir } \\
\text { Gudang }\end{array}$ & Larkin & \\
\hline Number of hazy observations (all years) & 221 & 171 & DOE \\
\hline Average number of hazy days (all years) & 21 & 15 & Calculation \\
\hline Average number of hazy days per year & 7 & 5 & Calculation \\
\hline Daily weighted average of PM10 for hazy days & 150.31 & 119.67 & DOE \\
\hline Normal weighted average (non-hazy days) & 54.41 & 39.24 & DOE \\
\hline Total population in Johor & 145,739 & 497,097 & $\begin{array}{l}\text { Department of } \\
\text { Salaysia }\end{array}$ \\
\hline $\begin{array}{l}\text { Factor for adjustment of dose-response } \\
\text { coefficient (F) }\end{array}$ & 0.483 & 0.483 & \\
\hline Unit economic value (UEV) & RM1 & RM1 & Calculation \\
\hline Economic values (EV) & RM83,233 & RM107,486 & Calculation (Equation 3) \\
\hline
\end{tabular}

\section{Conclusion}

This study provides the health-risk analysis of $\mathrm{PM}_{10}$ concentration in the ambient air of haze and non-haze periods in Pasir Gudang and Larkin. Health risks for all age categories in haze periods were higher than those in non-haze periods. The link between API and related outpatients was calculated using dose-response assessment. The average annual economic losses due to the outpatient health impact of haze were valued at RM83,233 and RM107,486 for Pasir Gudang and Larkin, respectively. This study only utilised data from health clinic outpatients. Hence, the admission statistics will be calculated based on the average number of inpatients at hospitals for more reliable finding. This shall be an area of future work.

The authors wish to acknowledge the financial and material support by Universiti Teknologi Malaysia and the Ministry of Higher Education (MOHE) for the GUP grant (Vot. No. 14H78).

\section{References}

[1] Abdul Rahman, H. (2013). Haze Phenomenon in Malaysia: Domestic or Trans-boundary Factor?

[2] Mohd Shahwahid H.O. The Economic Value of the June 2013 Haze Impacts on Peninsular Malaysia. Laguna, Philippines; 2016.

[3] Jamal et al. (2014)

[4] Yin, Y.W., Cheng, J.P., Duan, Y.S., (2011). Economic Evaluation of Residents' Health Hazard Caused by PM2.5 of Haze Pollution in a City. J. Environ. Health 28 (3), 250-252.

[5] Xie, Y.B., Chen, J., Li, W., (2014). An assessment of PM2.5 related health risks and impaired values of Beijing residents in a consecutive high-level exposure during heavy hazendays. Huan Jing Ke Xue 35, 1-8.

[6] Gao, M., Guttikunda, S.K., Carmichael, G.R., Wang, Y., Liu, Z., Stanier, C.O. (2015). Health impacts and economic losses assessment of the 2013 severe haze event in Beijing area. Sci. Total Environ. 511C, 553-561. 
[7] Mu, Q., and Zhang, S. (2013). An evaluation of the economic loss due to the heavy haze during January 2013 in China. China Environ. Sci. 33, 2087-2094.

[8] Zhao, W. Cheng, J. Li, D. Duan, Y., Wei, H., Ji, R. Wang, W. (2014). Urban ambient air quality investigation and health risk assessment during haze and non-haze periods in Shanghai, China Atmospheric Pollution Research 4(2013): 275-281.

[9] Pandey, J. S. Kumar, R., Devotta, S. (2005). Health risks of NO2, SPM and SO2 in Delhi (India). Atmospheric Environment. 39: 6868-6874.

[10] Kalaiarasan, M., Balasubramanian, R., Cheong, K.W.D., Tham, K.W., 2009. Trafficgenerated airborne particles in naturally ventilated multi-storey residential buildings of Singapore:bvertical distribution and potential health risks. Building and Environment 44: 1493-1500.

[11] Castro, D., Slezakova, K., Delerue-Matos, C., Alvim-Ferraz, M. D., Morais, S., Pereira, M. D. (2011). Polycyclic aromatic hydrocarbons in gas and particulate phases of indoor environments influenced by tobacco smoke: levels, phase distributions, and health risks. Atmospheric Environment. 45: 1799-1808.

[12] Zhao, W. C., Cheng, J. P., Guo, M. X., Cao, Q. F., Yin, Y. W., Wang, W. H. (2011).

[13] Ambient air particulate matter in the Yangtze River Delta Region, China: spatial, annual, and seasonal variations and health risks. Environmental Engineering Science. 28: 795-802.

[14] Othman J., Sahani M., Mahmud M., Sheikh Ahmad M.K. (2014). Transboundary smoke haze pollution in Malaysia: Inpa4ent health impacts and economic valua4on. Environ Pollut. Elsevier 189:194-201.

[15] World Health Organization, Children's Environmental Health, Accessed: 18 June 2018. 